\title{
Gene and cell therapy for muscle regeneration
}

\author{
Roberta Sessa Stilhano $^{1}$ - Leonardo Martins ${ }^{1}$ - Sheila Jean McNeill Ingham ${ }^{2}$. \\ João Bosco Pesquero ${ }^{1} \cdot$ Johnny Huard $^{3}$
}

Published online: 22 April 2015

(C) Springer Science+Business Media New York 2015

\begin{abstract}
Skeletal muscle injury and healing are multifactorial processes, involving three steps of healing: (1) degeneration and inflammation, (2) regeneration, and (3) fibrosis. Fibrous tissue hinders the muscle's complete recovery and current therapies fail in achieving total muscle recovery. Gene and cell therapy (or both) are potential future treatments for severe muscular injuries. Stem cells' properties associated with growth factors or/ and cytokines can improve muscle healing and permit long-term recovery.
\end{abstract}

Keywords Gene therapy · Cell therapy · Muscle injury · Fibrosis $\cdot$ Stem cell $\cdot$ Growth factor

\section{Introduction}

Skeletal muscle injuries are the most frequent sports-related lesions and present a challenge in primary care and sports

This article is part of the Topical Collection on Muscle Injuries

Roberta Sessa Stilhano and Leonardo Martins contributed equally to this work.

Roberta Sessa Stilhano

robertasessa@gmail.com

1 Biophysics Department, Federal University of São Paulo - UNIFESP, Rua Mirassol, 207 - Vila Clementino, 04044-010 São Paulo, Brazil

2 Department of Orthopaedic Surgery, Federal University of São Paulo, São Paulo, Brazil

3 Stem Cell Research Center, Department of Orthopaedic Surgery, and Department of Bioengineering, University of Pittsburgh, Pittsburgh, PA, USA medicine [1]. Muscle injuries occur through a variety of mechanisms, including direct trauma (e.g., lacerations, contusions, and strains) and indirect causes (e.g., ischemia and neurological dysfunction) [2]. After injury, the muscle undergoes different healing stages, consisting of degeneration, inflammation, regeneration, and fibrosis [2]. Complete recovery after an injury is compromised due to the development of fibrous tissue $[1,3]$. Skeletal muscle fibrosis could be defined as an abnormal chronic increase in extracellular connective tissue that interferes with function [4]. The presence of fibrosis delays the muscle's full functional recovery and injury may become recurrent [3]. Current therapy for muscular injuries consists of conventional clinical treatments including the RICE (rest, ice, compression, and elevation) protocol, nonsteroidal anti-inflammatory drugs, and intramuscular corticosteroids, which have a limited efficacy in preventing or treating the formation of posttraumatic muscle fibrosis $[3,5,6]$.

As conventional therapy does not provide complete injury regeneration, novel therapies could represent a new treatment option for muscular injuries. Gene and cellular therapies, or the combination of both, appear as the main future therapies for muscle injury treatment.

This review focuses on these two novel therapeutic approaches: gene and cell therapies for muscular injuries. We will discuss the concept of gene therapy, the gene transfer process, and the administration of growth factors using gene therapy methodology. We will also discuss the main cell therapies and the characteristics of each cell type. Finally, we will discuss the combination of gene therapy and cell therapy. By clarifying our understanding of these processes, it may be possible to develop more effective approaches to improve muscle healing and obtain complete functional recovery. 


\section{Gene therapy}

Gene therapy is the transfer of nucleic acids into the cells with the aim of altering the course of a medical condition or disease, restoring function, establishing new ones, or altering the expression of an endogenous gene in a cell $[7,8]$. Nucleic acids are DNA molecules that encode a functional protein into a cell [7], and many vehicles, named vectors, are used to transfer nucleic acids into the cells. Vectors can be divided into viral and nonviral delivery systems. The viral systems most frequently used in clinical trials are derived from retrovirus, lentivirus, adenovirus, and adeno-associated virus (AAV) (http://www.abedia.com/wiley/vectors.php). Nonviral vectors include plasmids that are a circle of double-stranded DNA that replicates in bacteria or can be chemically synthesized [8].

Plasmid vectors are superior to viral systems in terms of biosecurity, but are generally inferior in terms of efficiency of gene transfer [9]. Research to develop new systems of nonviral gene transfer has grown. Electroporation [10], sonoporation [11] use of lipoplexes [12], polyplexes [13], transfection by hydrodynamics [14], and nucleofection [15] are examples of nonviral gene transfers that are efficient and comparable to viral systems. Vectors containing the therapeutic nucleic acid can be introduced into patients using two techniques: ex vivo in which cells are removed, genetically modified, and transplanted back into the same recipient and in vivo therapy in which the genetic material is introduced directly into the patient (Fig. 1) [7].

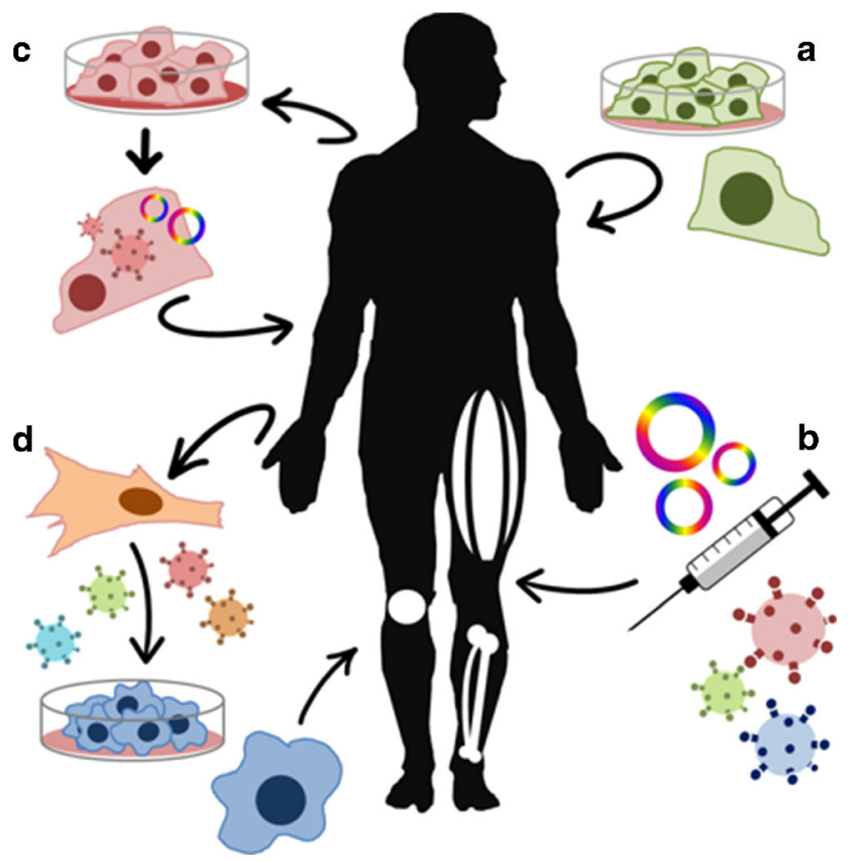

Fig. 1 Schematic gene and cell therapy procedures. Cell therapy (a), gene therapy based on plasmid or viral vectors (b), combined therapy or gene therapy ex vivo (c), and cellular changes (i.e., reprogramming iPS cells) (d)
Gene therapy has been used in pre-clinical trials to treat muscular injuries, especially to treat muscular fibrosis. The control of tissue fibrosis is a critical factor for injured tissue repair and the most explored pathway involves TGF- $\beta$ (transforming growth factor beta). TGF- $\beta 1$ is expressed during myogenesis, and its spatial and temporal expression in the developing connective tissue is correlated with fiber-type composition of the myotubes. Immediately after muscle injury, a very well-coordinated repair process begins. This process includes the release of growth factors and cytokines, proliferation, and migration of macrophages and fibroblasts. These cells increased the production of extracellular matrix components (ECMs). Post-injury tissue resolution is characterized by ECM accumulation, which may be normal or abnormal, depending on the time and severity of the injury. The inflammatory response is useful for cleaning debris from myofibrillar and modulation of regeneration, and the formation of new myofibers starts with satellite cell activation and the proliferation, differentiation, and fusion of the myocytes are the subsequent events [16]. Genes chosen for delivery are diverse and have shown different results; the myogenic regulation involving myostatin and follistatin genes has been extensively studied. There is a tendency to use the AAV [17], and it is emerging as one of the most popular gene delivery systems because of a lack of pathogenicity in humans, mild immune response, and its long-term and efficient transgene expression in various cells [18]. Some AAVs do not integrate into the cell genome and can exist long term in non-dividing cells.

An adeno-associated vector containing the myostatin propeptide (AAV2-mediated MPRO) promoted healing of skeletal muscle in mice by inhibiting myostatin. These results suggest that this inhibition can be applied in the treatment of myopathies and skeletal muscle injuries [19]. On the other hand, AAV expressing a serotype 1 follistatin isoform (AAV1-FS344) induced an extensive and pronounced increase in strength and muscle mass when injected into the quadriceps of primates [20]. The attenuation of the pro-fibrotic TGF- $\beta 1$ in the absence of myostatin has been shown [19].

Other myogenesis-related genes, although less studied, have emerged. The systemic delivery and overexpression of muscle-specific human gene MG53, by AAV in an animal model with muscular dystrophy and congestive heart defect (CHD), promote the repair of the sarcolemmal membrane, pathology mitigation, and improved muscle and heart function [21].

In addition to genes, proteins involved in the regulation of TGF- $\beta$ have also been explored; the LTBP4 protein (TGF- $\beta$ latent-binding protein 4 ), which regulates the release of TGF- $\beta$ to the extracellular matrix, increases bioavailability, and has been identified as a modulator in the context of muscular dystrophy fibrosis in mice [22].

Proteins and growth factors have also been used to enhance angiogenesis and myogenesis. Piccioni et al. [23•] have 
shown that the Shh gene (sonic hedgehog) was able to activate the expression of myogenic and angiogenic factors thus increasing the capacity of muscle regeneration after injury. The IGF-1 (insulin-like growth factor) gene was used to treat muscle injury and was effective in regenerating muscle fibers and could attract bone marrow stem cells to the injury site and, with this, accelerate tissue repair [24, 25]. An AAV expressing VEGF (vascular endothelial growth factor) was injected 5 days after muscular injury, and the treated group showed a better and faster muscle regeneration [26].

During the planning of therapies for muscle injuries, both the increase and the suppression of gene expression, the production of the final protein and its likely outcome in tissue resolution should be considered.

\section{Cell therapy}

Cell therapy involves the use of cells for treatment. In the case of muscle damage, the cells that have been used most frequently in pre-clinical trials are as follows: MSC (mesenchymal stem cell), myoblast, SC (satellite cell), MDSC (musclederived stem cell), and iPSC (induced pluripotent stem cell).

MSCs are non-hematopoietic multipotent stem cells that adhere to a culture plate [27]. MSCs have the ability to renew and differentiate into multiple lineages of connective tissue, including bone, fat, cartilage, tendon, muscle, and bone marrow stromal cells [27]. These cells were first described by Friedenstein who found that MSCs adhere to culture plates, resemble fibroblasts in vitro, and form colonies [28]. MSCs are present in all adult tissues and in the wall of fetal tissue vessels as part of the pericyte population [29]. In vivo, MSCs are identified by expressing CD146 and CD271, and within the adipose tissue as part as the CD34-positive population [30]. A very rich source of MSC is the adipose tissue and these cells are called ADSC (adipose-derived stem cell). Peçanha et al. [31] showed that ADSCs were able to accelerate muscle recovery of treated animals.

SCs are a heterogeneous group of adult cells, defined by their location between the basal lamina and the sarcolemma of the muscle fiber. They are characterized by the expression of Pax7, Pax3, c-Met, M-cadherin, CD34, Syndecan-3, and calcitonin [32]. In response to fiber damage, these normally quiescent cells activate and proliferate; this process is largely controlled by Myf5 and MyoD. Few Pax $7^{+} \mathrm{MyoD}^{-}$cells return to a quiescent state, and the majority $\mathrm{Pax} 7^{+} \mathrm{MyoD}^{+}$commit to differentiation, exit the cell cycle, and fuse with each other to generate new repaired myofibrils [33]. Satellite cells are rare, accounting for less than $5 \%$ of total myofiber nuclei in humans [34]. One of the problems in the use of myoblast therapy is the muscle biopsies tend to yield a small amount of cells. There is currently a debate about the minimum number of cells needed for an effective therapy but there is evidence that significantly fewer satellite cells are needed to regenerate muscle tissue. Remarkably, transplantation of even one satellite cell is sufficient to give rise to new myofibers and satellite cells [34]. Despite this impressive finding, it is very likely that many more satellite cells will be required when multiple muscle groups are targeted in patients. Unfortunately, ex vivo expansion of murine satellite cells significantly impairs in vivo engraftment potential following transplantation [34]. Fan et al. [35] observed a rapid death of injected myoblasts after transplantation into injured or uninjured muscles of dystrophic mice $(\mathrm{mdx})$ [35].

Lim et al. [36] used myoblast transplantation in a preclinical study to treat X-linked myotubular myopathy (XLMTM), an isogenic muscle disease characterized by progressive wasting of skeletal muscle, weakness, and premature death of affected male offspring [36]. The authors observed, in treated mice, an increase in skeletal muscle mass, augmented force generation, and increased nerve evoked skeletal muscle action potential amplitude [36].

MDSCs are multipotent stem cells that were isolated from mouse skeletal muscle and are obtained through a series of steps of plating on collagen plates [37, 38]. Qu-Petersen et al. [38] isolated three different subpopulations of cells from skeletal muscle: although two of them exhibited SC-like characteristics, the third population comprised cells that retained their phenotype for several passages and showed the ability to differentiate into muscle, endothelial and neural lineages. The MDSCs have a high expression of Sca-1, very low levels of viementin (a fibroblast marker), and low levels of desmin and other markers of muscle differentiation [38]. Ota et al. [39] showed that injection of MDSCs 4 days after injury increased angiogenesis and reduced scar tissue. In addition, high levels of VEGF (vascular endothelial growth factor) were found 1 week after injection. In addition, MDSCs expressed high levels of antioxidant, GSH (glutathione) and superoxide dismutase, allowing greater survival of these cells after injection [40, 41].

iPSC are commonly generated by transduction of Oct4, Sox2, Klf4, and Myc into somatic cells in order to create pluripotent cells [42]. They can undergo unlimited selfrenewal and maintain the embryonic stem cell (ESC)-like ability to differentiate into all three germ layers. iPSCs can potentially provide unlimited autologous cells for therapy and therefore hold great promise for regenerative medicine and they have been used for the production of myoblast and satellite cells in vitro. Stem cell-derived myocytes were proven to be a valid cell source, primarily not only because of their good ability to differentiate in vitro but also because of their selfrenewing ability that allows to maintain them in vitro for a long time with no genetic alterations [43]. iPSCs have been used in pre-clinical studies to treat muscular dystrophies. Tedesco et al. [44•] reprogrammed fibroblasts and myoblasts from limb-girdle muscular dystrophy and observed functional 
amelioration of the dystrophic phenotype and restoration of the depleted progenitors. Abujarour et al. [45] used these cells to generate iPSC lines from fibroblasts of four patients with Duchenne and Becker muscular dystrophies. The authors observed an efficient and rapid myogenesis potential in these cells.

There are many clinical trials using stem cells to treat muscular dystrophies. However, there is only one looking at muscular injury, not involving dystrophy. It is a phase I and II study that uses stem cell therapy to improve muscle function of patients with partly denervated arm muscles (NCT00755586).

Currently, the major concern is to retain these living cells at the injury site so that they can have a prolonged effect. Distefano et al. [46॰] used electrical stimulus and showed that the cells remained longer at the site of injury. Park et al. [47•] used losartan associated with ADSC and achieved a greater reduction in fibrosis following injury.

\section{Future therapies: gene and cell therapy}

The uses of gene and cell therapies are promising, and the combination of the properties of stem cells with growth factors may be a future alternative therapy for faster recovery from a muscle injury. A patient-specific treatment can be designed associating gene therapy and stem cells. A variety of gene therapy methods using plasmids, virus (lentivirus, adenovirus, retrovirus), recombinases (phiC31, Bxb1, Cre), transposons (Sleeping Beauty, Piggy Bac), and the new systems TALEN and CRISPR is available to overexpress factors, correct one deficient gene, or permit a long-term permanency of stem cells in the tissue. The combination stem cells + gene therapy has been used in pre-clinical studies to treat muscular dystrophies. Zhao et al. [48] reprogramed mdx fibroblasts, using phiC31 integrase to insert a single copy of the reprogramming genes at a safe location in the genome and produced iPSC. They used Bxb1 integrase to add the therapeutic full-length dystrophin cDNA to the iPSC in a site-specific manner. Unwanted DNA sequences, including the reprogramming genes, were then precisely deleted with Cre resolvase. Myogenically differentiated cells derived from $\mathrm{mdx}$ iPSC could be engrafted in $\mathrm{mdx} /$ SCID mice and restored dystrophin expression in myofibers in vivo. Gullota et al. [49] used MSCs genetically modified with scleraxis (Scx) - a basic helix-loop-helix transcription factor that is thought to direct tendon development during embryogenesis. The purpose of the study was to determine if the application of MSCs transduced with adenoviralmediated scleraxis (Ad-Scx) could improve regeneration of the tendon-bone insertion site in a rat rotator cuff repair model. The augmentation of acutely injured rotator cuffs with Scxtransduced MSCs may improve rotator cuff tendon healing and reduce the incidence of re-tears.

\section{Conclusions}

Functional recovery of severe muscular injuries remains limited; the major problem is the formation of scar tissue and functional impairment, and conventional therapies have limited results. Researches have been working on the development of new therapies in order to improve the muscle healing. The delivery of growth and myogenic factors to the injured muscle through gene therapy has shown promising results in preclinical studies. Since 1989, gene therapy has been transformed into a reality with more than 2000 clinical trials around the world (www.abedia.com). Gene therapy can be a novel approach for the treatment of muscular injury.

Cell therapy has had more pre-clinical studies than gene therapy; however, there is only one clinical trial evaluating the use of cells for muscular injury. Stem cells can be used to treat the muscle injury as long as the maintenance of the cells in the injured tissue can be prolonged. Associating gene and cell therapy may solve this concern.

This review has discussed the latest gene transfer methodologies that can increase the life span of stem cell in the tissue, promoting long-term healing. The purpose of this review was to illustrate the highlights as well as hurdles that remain for developing successful gene and cell therapy application.

\section{Compliance with Ethics Guidelines}

Conflict of Interest Roberta Sessa Stilhano, Leonardo Martins, Sheila Jean McNeill Ingham, and João Bosco Pesquero declare that they have no conflict of interest.

Johnny Huard receives consulting fees and royalties from Cook MyoSite Inc.

Human and Animal Rights and Informed Consent This article does not contain any studies with human or animal subjects performed by any of the authors.

\section{References}

Papers of particular interest, published recently, have been highlighted as:

- Of importance

1. Baoge L, Van Den Steen E, Rimbaut S, Philips N, Witvrouw E, Almqvist KF, et al. Treatment of skeletal muscle injury: a review. ISRN Orthop. 2012;2012:689012. doi:10.5402/2012/689012.

2. Huard J, Li Y, Fu FH. Muscle injuries and repair: current trends in research. J Bone Joint Surg Am. 2002;84-a(5):822-32.

3. Gharaibeh B, Chun-Lansinger Y, Hagen T, Ingham SJ, Wright V, $\mathrm{Fu} \mathrm{F}$, et al. Biological approaches to improve skeletal muscle healing after injury and disease. Birth Defects Res C Embryo Today Rev. 2012;96(1):82-94. doi:10.1002/bdrc.21005.

4. Lieber RL, Ward SR. Cellular mechanisms of tissue fibrosis. 4. Structural and functional consequences of skeletal muscle fibrosis. 
Am J Physiol Cell Physiol. 2013;305(3):C241-52. doi:10.1152/ ajpcell.00173.2013.

5. Jarvinen MJ, Lehto MU. The effects of early mobilisation and immobilisation on the healing process following muscle injuries. Sports Med (Auckland, NZ). 1993;15(2):78-89.

6. Paoloni JA, Milne C, Orchard J, Hamilton B. Non-steroidal antiinflammatory drugs in sports medicine: guidelines for practical but sensible use. Br J Sports Med. 2009;43(11):863-5. doi:10.1136/ bjsm.2009.059980.

7. Kay MA, Liu D, Hoogerbrugge PM. Gene therapy. Proc Natl Acad Sci U S A. 1997;94(24):12744-6.

8. Ponder KP. Vectors in gene therapy. In: Kresina T, editor. An introduction to molecular medicine and gene therapy. New York: WileyLiss; 2000. p. 77-112.

9. Wood KJ, Fry J. Gene therapy: potential applications in clinical transplantation. Exp Rev Mol Med. 1999;1999:1-20. doi:10. 1017/S1462399499000691.

10. Yang JC, Liu J, Yang XW, Tang JG. Gene therapy for diabetic rats by electroporational transfer of naked plasmid with human pre-proinsulin gene into skeletal muscle. Biotechnol Lett. 2002;24(10): $851-5$.

11. Newman CM, Bettinger T. Gene therapy progress and prospects: ultrasound for gene transfer. Gene Ther. 2007;14(6):465-75. doi: 10.1038/sj.gt.3302925.

12. Wagner E, Culmsee C, Boeckle S. Targeting of polyplexes: toward synthetic virus vector systems. Adv Genet. 2005;53PA:333-54. doi:10.1016/S0065-2660(05)53013-X.

13. Boussif O, Lezoualc'h F, Zanta MA, Mergny MD, Scherman D, Demeneix B, et al. A versatile vector for gene and oligonucleotide transfer into cells in culture and in vivo: polyethylenimine. Proc Natl Acad Sci U S A. 1995;92(16):7297-301.

14. Herweijer H, Wolff JA. Gene therapy progress and prospects: hydrodynamic gene delivery. Gene Ther. 2007;14(2):99-107. doi:10. 1038/sj.gt.3302891.

15. Zeitelhofer M, Vessey JP, Thomas S, Kiebler M, Dahm R. Transfection of cultured primary neurons via nucleofection. In: Crawley N J et al., Current Protocols in neuroscience / editorial board, Chapter 4:Unit4 32. 2009. doi:10.1002/0471142301. ns0432s47.

16. Burks TN, Cohn RD. Role of TGF-beta signaling in inherited and acquired myopathies. Skelet Muscle. 2011;1(1):19. doi:10.1186/ 2044-5040-1-19.

17. Li Y, Li J, Zhu J, Sun B, Branca M, Tang Y, et al. Decorin gene transfer promotes muscle cell differentiation and muscle regeneration. Mol Ther:J Am Soc Gene Ther. 2007;15(9):1616-22. doi:10. 1038/sj.mt.6300250.

18. Chen C, Akerstrom V, Baus J, Lan MS, Breslin MB. Comparative analysis of the transduction efficiency of five adeno associated virus serotypes and VSV-G pseudotype lentiviral vector in lung cancer cells. Virol J. 2013;10:86. doi:10.1186/1743-422x-10-86.

19. Zhu J, Li Y, Shen W, Qiao C, Ambrosio F, Lavasani M, et al. Relationships between transforming growth factor-beta1, myostatin, and decorin: implications for skeletal muscle fibrosis. J Biol Chem. 2007;282(35):25852-63. doi:10.1074/jbc. M704146200.

20. Kota J, Handy CR, Haidet AM, Montgomery CL, Eagle A, RodinoKlapac LR, et al. Follistatin gene delivery enhances muscle growth and strength in nonhuman primates. Sci Transl Med. 2009;1(6): 6ra15. doi:10.1126/scitranslmed.3000112.

21. He B, Tang RH, Weisleder N, Xiao B, Yuan Z, Cai C, et al. Enhancing muscle membrane repair by gene delivery of MG53 ameliorates muscular dystrophy and heart failure in deltaSarcoglycan-deficient hamsters. Mol Ther J Am Soc Gene Ther. 2012;20(4):727-35. doi:10.1038/mt.2012.5.

22. Heydemann A, Ceco E, Lim JE, Hadhazy M, Ryder P, Moran JL, et al. Latent TGF-beta-binding protein 4 modifies muscular dystrophy in mice. J Clin Invest. 2009;119(12):3703-12. doi:10. 1172/jci39845.

23. Piccioni A, Gaetani E, Neri V, Gatto I, Palladino M, Silver M, et al. Sonic hedgehog therapy in a mouse model of age-associated impairment of skeletal muscle regeneration. J Gerontol A Biol Sci Med Sci. 2014;69(3):245-52. doi:10.1093/gerona/glt076. The authors used Shh (Sonic hedgehog) as a therapy for skeletal muscle regeneration of old mice for the first time. This embryonic gene increased muscle regeneration and reduced fibrosis.

24. Sacco A, Doyonnas R, LaBarge MA, Hammer MM, Kraft P, Blau HM. IGF-I increases bone marrow contribution to adult skeletal muscle and enhances the fusion of myelomonocytic precursors. J Cell Biol. 2005;171(3):483-92. doi:10.1083/jcb.200506123.

25. Schertzer JD, Lynch GS. Comparative evaluation of IGF-I gene transfer and IGF-I protein administration for enhancing skeletal muscle regeneration after injury. Gene Ther. 2006;13(23):165764. doi:10.1038/sj.gt.3302817.

26. Arsic N, Zacchigna S, Zentilin L, Ramirez-Correa G, Pattarini L, Salvi A, et al. Vascular endothelial growth factor stimulates skeletal muscle regeneration in vivo. Mol Ther. 2004;10(5):844-54. doi:10. 1016/j.ymthe.2004.08.007.

27. Meirelles Lda S, Nardi NB. Murine marrow-derived mesenchymal stem cell: isolation, in vitro expansion, and characterization. $\mathrm{Br} \mathrm{J}$ Haematol. 2003;123(4):702-11.

28. Friedenstein AJ, Chailakhjan RK, Lalykina KS. The development of fibroblast colonies in monolayer cultures of guinea-pig bone marrow and spleen cells. Cell Tissue Kinet. 1970;3(4):393-403.

29. Crisan M, Yap S, Casteilla L, Chen CW, Corselli M, Park TS, et al. A perivascular origin for mesenchymal stem cells in multiple human organs. Cell Stem Cell. 2008;3(3):301-13. doi:10.1016/j.stem. 2008.07.003.

30. Sensebe L, Bourin P, Tarte K. Good manufacturing practices production of mesenchymal stem/stromal cells. Hum Gene Ther. 2011;22(1):19-26. doi:10.1089/hum.2010.197.

31. Pecanha R, Bagno LL, Ribeiro MB, Robottom Ferreira AB, Moraes MO, Zapata-Sudo G, et al. Adipose-derived stem-cell treatment of skeletal muscle injury. J Bone Joint Surg Am. 2012;94(7):609-17. doi:10.2106/jbjs.k.00351.

32. Motohashi N, Asakura Y, Asakura A. Isolation, culture, and transplantation of muscle satellite cells. J Visual Exp. 2014; 86. doi:10. 3791/50846.

33. Fishman JM, Tyraskis A, Maghsoudlou P, Urbani L, Totonelli G, Birchall MA, et al. Skeletal muscle tissue engineering: which cell to use? Tissue Eng B Rev. 2013;19(6):503-15. doi:10.1089/ten.TEB. 2013.0120.

34. Bareja A, Billin AN. Satellite cell therapy - from mice to men. Skelet Muscle. 2013;3(1):2. doi:10.1186/2044-5040-3-2.

35. Fan Y, Maley M, Beilharz M, Grounds M. Rapid death of injected myoblasts in myoblast transfer therapy. Muscle Nerve. 1996;19(7): 853-60. doi:10.1002/(SICI)1097-4598(199607)19:7<853::AIDMUS7>3.0.CO;2-8.

36. Lim HJ, Joo S, Oh SH, Jackson JD, Eckman DM, Bledsoe TM, et al. Syngeneic myoblast transplantation improves muscle function in a murine model of X-linked myotubular myopathy. Cell Transplant. 2014. doi: $10.3727 / 096368914 \times 683494$.

37. Gharaibeh B, Lu A, Tebbets J, Zheng B, Feduska J, Crisan M, et al. Isolation of a slowly adhering cell fraction containing stem cells from murine skeletal muscle by the preplate technique. Nat Protoc. 2008;3(9):1501-9. doi:10.1038/nprot.2008.142.

38. Qu-Petersen Z, Deasy B, Jankowski R, Ikezawa M, Cummins J, Pruchnic R, et al. Identification of a novel population of muscle stem cells in mice: potential for muscle regeneration. J Cell Biol. 2002;157(5):851-64. doi:10.1083/jcb.200108150.

39. Ota S, Uehara K, Nozaki M, Kobayashi T, Terada S, Tobita K, et al. Intramuscular transplantation of muscle-derived stem cells 
accelerates skeletal muscle healing after contusion injury via enhancement of angiogenesis. Am J Sports Med. 2011;39(9):191222. doi:10.1177/0363546511415239.

40. Drowley L, Okada M, Beckman S, Vella J, Keller B, Tobita K, et al. Cellular antioxidant levels influence muscle stem cell therapy. Mol Ther J Am Soc Gene Ther. 2010;18(10):1865-73. doi:10.1038/mt. 2010.160.

41. Urish KL, Vella JB, Okada M, Deasy BM, Tobita K, Keller BB, et al. Antioxidant levels represent a major determinant in the regenerative capacity of muscle stem cells. Mol Biol Cell. 2009;20(1): 509-20. doi:10.1091/mbc.E08-03-0274.

42. Takahashi K, Yamanaka S. Induction of pluripotent stem cells from mouse embryonic and adult fibroblast cultures by defined factors. Cell. 2006;126(4):663-76. doi:10.1016/j.cell.2006.07.024.

43. Salani S, Donadoni C, Rizzo F, Bresolin N, Comi GP, Corti S. Generation of skeletal muscle cells from embryonic and induced pluripotent stem cells as an in vitro model and for therapy of muscular dystrophies. J Cell Mol Med. 2012;16(7):1353-64. doi:10. 1111/j.1582-4934.2011.01498.x.

44. Tedesco FS, Gerli MF, Perani L, Benedetti S, Ungaro F, Cassano M, et al. Transplantation of genetically corrected human iPSC-derived progenitors in mice with limb-girdle muscular dystrophy. Sci Transl Med. 2012;4(140):140ra189. doi:10.1126/scitranslmed.3003541. The authors used human induced pluripotent stem cells (iPSC) to treat limb-girdle muscular dystrophy. The iPSC strategy allowed the derivation and propagation, in culture, of a population of MAB-like mesodermal generated from adult somatic cells.

45. Abujarour R, Bennett M, Valamehr B, Lee TT, Robinson M, Robbins D, et al. Myogenic differentiation of muscular dystrophy-specific induced pluripotent stem cells for use in drug discovery. Stem Cells Transl Med. 2014;3(2):149-60. doi:10.5966/ sctm. 2013-0095.

46. Distefano G, Ferrari RJ, Weiss C, Deasy BM, Boninger ML, Fitzgerald GK, et al. Neuromuscular electrical stimulation as a method to maximize the beneficial effects of muscle stem cells transplanted into dystrophic skeletal muscle. PLoS One. 2013;8(3):e54922. doi:10.1371/journal.pone.0054922. This article describes a method to maximize the permanency and effect of muscle stem cells in muscle dystrophy. This is a big advance in the transplatation field.

47. Park JK, Ki MR, Lee EM, Kim AY, You SY, Han SY, et al. Losartan improves adipose tissue-derived stem cell niche by inhibiting transforming growth factor-beta and fibrosis in skeletal muscle injury. Cell Transplant. 2012;21(11):2407-24. doi:10.3727/ $096368912 \times 637055$. The maintenance of the cells in their niche after transplantation is a hard challenge. In this work the authors used losartan, an AT1 receptor blocker, to reduce fibrosis and permit long term permanency of the adipose tissue-derived stem cells.

48. Zhao C, Farruggio AP, Bjornson CR, Chavez CL, Geisinger $\mathrm{JM}$, Neal TL, et al. Recombinase-mediated reprogramming and dystrophin gene addition in $\mathrm{mdx}$ mouse induced pluripotent stem cells. PLoS One. 2014;9(4):e96279. doi:10.1371/ journal.pone.0096279.

49. Gulotta LV, Kovacevic D, Packer JD, Deng XH, Rodeo SA. Bone marrow-derived mesenchymal stem cells transduced with scleraxis improve rotator cuff healing in a rat model. Am J Sports Med. 2011;39(6):1282-9. doi:10.1177/0363546510395485. 